\title{
EDUCADOR SUFICIENTEMENTE BOM: UMA RELEITURA WINNICOTTIANA DOS INDICADORES DO IRDI ${ }^{1}$
}

\author{
GOOD ENOUGH CAREGIVER: IRDI METHODOLOGY INDICATORS AS READ FROM WINNICOTT \\ EDUCADOR SUFICIENTEMENTE BUENO: UNA RELECTURA WINNICOTTIANA DE LOS \\ INDICADORES DEL IRDI
}

\author{
Mariana Farias Puccinelli \\ Milena da Rosa Silva*
}

\begin{abstract}
RESUMO
Este artigo aborda o conceito de educador suficientemente bom. Tal construção teórica parte da releitura winnicottiana dos indicadores da metodologia IRDI (Indicadores de Risco para o Desenvolvimento Infantil). Assim, buscar-se-á compreender de que maneiras os educadores dos berçários e maternais auxiliam a dar andamento aos processos do amadurecimento dos bebês dos quais cuidam, utilizando-se, para isso, da teoria do amadurecimento proposta pelo psicanalista inglês D. W. Winnicott. Compreende-se que os profissionais das creches contribuem de forma importante para a constituição psíquica dos bebês, pois proporcionam continuidade aos principais processos desta: integração, personalização e capacidade para relacionamentos. Nesse sentido, esses educadores, quando atuando de maneira suficientemente boa, proporcionam continuidade e suplência ao papel do cuidador primordial, na maioria das vezes, exercido pela figura materna. Considerando o potencial constitutivo do fazer dos educadores de berçários e maternais, evidencia-se a necessidade e a relevância de propostas de formação especializadas para esses profissionais.
\end{abstract}

Palavras-chave: IRDI. Metodologia IRDI. Creches. Educação infantil. Teoria do amadurecimento de Winnicott.

\section{ABSTRACT}

This paper addresses the concept of a good enough caregiver. Such notion is based on the view of IRDI (Clinical Risk Indicators for Child

\footnotetext{
Texto recebido em 23 de outubro de 2018 e aprovado para publicação em 2 de setembro de 2019.

${ }^{1}$ Este artigo é parte integrante da dissertação de mestrado intitulada $A$ sustentação do corpo como possibilidade de existência: os processos de integração psicossomática no âmbito da educação infantil, de Mariana Farias Puccinelli, sob orientação da Prof. ${ }^{a}$ Milena da Rosa Silva.

* Doutoranda no Núcleo de Infância e Família (Nudif) do Programa de Pós-Graduação em Psicologia da Universidade Federal do Rio Grande do Sul (UFRGS), mestra em Psicanálise Clínica e Cultura pela UFRGS e psicóloga clínica. Endereço: Rua Eça de Queirós, 384, ap. 301 - Bairro Petrópolis, Porto Alegre-RS, Brasil. CEP: 90670020. Telefone: (51) 98260-7215. E-mail: puccinellimariana@gmail.com.

** Doutora em Psicologia pela UFRGS, docente e pesquisadora no Programa de Pós-Graduação Psicanálise: Clínica e Cultura e na Graduação em Psicologia - Instituto de Psicologia da UFRGS, psicóloga. Endereço: Rua Reis Louzada, 284, ap. 302 - Bairro Petrópolis, Porto Alegre-RS, Brasil. CEP: 90630-130. Telefone: (51) 99138-9668. E-mail: milenarsilva@hotmail.com.
} 
Development) methodology indicators according to Winnicott's approach. We seek to understand in what ways daycare children caregivers facilitate the maturational processes of the babies they care for, based on D. W. Winnicott's theory of emotional development. It is understood that daycare centres caregivers play a significant role in the psychic constitution of babies, considering they provide an extension to processes such as integration, personalization and socialization. When acting out in a good enough manner, they help to create a sense of continuity and their role substitutes that of the babies' primordial caregiver, often performed by the mother figure. Because their work has a potentially constitutive role in children's lives, it becomes clear not only that these professionals need specialized training, but how relevant this training is.

Keywords: IRDI. IRDI methodology. Daycare centres. Early childhood education. Maturational processes.

\section{RESUMEN}

Este artículo intenta abordar el concepto de un educador suficientemente bueno. Esta noción se basa en los indicadores de la metodología IRDI (Indicadores de riesgo clínico en el desarrollo infantil) según propone Winnicott. Por lo tanto, buscamos comprender de qué manera los educadores de guarderías y otros centros de educación infantil facilitan los procesos de maduración de los bebés a los que cuidan, según la teoría del desarrollo emocional de D. W. Winnicott. Se entiende que los educadores de guarderías desempeñan un papel importante en la constitución psíquica de los bebés ya que proporcionan una extensión de sus procesos tales como la integración, la personalización y la socialización. Así, esos educadores cuando actúan de manera suficientemente buena, ayudan a crear un sentido de continuidad y suplencia al papel del cuidador primordial de los bebés, a menudo realizado por la figura de la madre. Teniendo en cuenta que su trabajo tiene potencialmente un papel constitutivo en la vida de los niños, quedan claras la necesidad y la relevancia de una capacitación especializada para estos profesionales.

Palabras clave: IRDI. Metodología IRDI. Guarderías. Educación infantil. Teoría de la maduración de Winnicott.

\section{EDUCADOR SUFICIENTEMENTE BOM: UMA RELEITURA WINNICOTTIANA DOS INDICADORES DO IRDI}

\footnotetext{
preponderância da escolha da creche como cuidado alternativo dos bebês bem como o número elevado de horas em que essas crianças passam sob 1 cuidados dos educadores da educação infantil, são aspectos que levantam
} 
importantes questões a respeito da função desse profissional para a constituição psíquica dos bebês dos quais cuidam. Nesse sentido, diferentes estudos têm abordado esses aspectos, buscando delimitar qual papel o educador desempenha em relação a essas crianças, em seus primeiros meses de vida.

Nesse âmbito, o emprego da metodologia IRDI (indicadores de risco para o desenvolvimento infantil) tem importante espaço, pois se constitui como estratégia para conceder ao professor papel privilegiado na observação do desenvolvimento infantil (Kupfer, Bernardino, \& Mariotto, 2014). Esse conjunto de procedimentos, adaptado ao contexto das creches, é baseado no IRDI, criado, em um primeiro momento, para a avaliação da interação mãe e bebê em consultas pediátricas (Kupfer, Rocha, Cavalcanti, Escobar, Fingerman, 2008).

O IRDI, instrumento no qual se baseia a metodologia IRDI, tem embasamento psicanalítico, composto por 31 indicadores de risco para o desenvolvimento infantil, que enfocam a relação entre a mãe e o bebê. Esses englobam quatro diferentes faixas do 0 aos 18 meses de vida, sendo 0-4 meses incompletos, 4-8 meses, 8-12 meses e 12-18 meses. O estudo de validação dos IRDI contou com a avaliação de 727 crianças, divididas em centros pediátricos de nove cidades brasileiras (Kupfer et al., 2009). Objetivou identificar se, efetivamente, os indicadores tinham a capacidade preditora de risco para o desenvolvimento infantil. $^{2}$

Os indicadores atentam para a relação entre a mãe e o bebê, sendo esse um aspecto inédito do instrumento em relação às demais avaliaçôes utilizadas, cujo enfoque se dá, em maior parte, na criança. Assim, a presença do indicador, na faixa etária esperada, demonstra saúde, e sua ausência se caracteriza como evidência de risco para o desenvolvimento (Kupfer et al., 2008). O instrumento se baseia em quatro eixos teóricos principais, os quais partem especialmente das concepçóes lacanianas sobre a constituição do sujeito psíquico, sendo eles: estabelecimento da demanda (ED), suposição do sujeito (SS), alternância presença e ausência (AP) e função paterna (FP). A divisão dos eixos é realizada com fins didáticos, entretanto, na constituição psíquica do pequeno sujeito, estes não se estruturam de forma separada ou autônoma. Eles seriam complementares, sendo o trabalho materno o que atuaria de forma a costurá-los, produzindo a instalação de um sujeito psíquico (Kupfer et al., 2009).

Ampliando as possibilidades de utilização do IRDI, um estudo conduzido por Bernardino e Mariotto (2010) propôs um conjunto de intervenções baseadas

2 De maneira geral, o estudo de validação demonstrou que o instrumento tem capacidade de prever problemas para o desenvolvimento. Contudo alguns grupos de indicadores podem ser utilizados para a predição de risco psíquico. Ver mais em Kupfer et al., 2009. 
no instrumento, constituindo, assim, a metodologia IRDI. Justifica-se essa ampliação por entender-se que as educadoras também exercem papel de agentes de promoção de saúde mental dos bebês (Bernardino, Vaz, Quadros, \& Vaz, 2008). A metodologia IRDI divide-se em três momentos principais: formação com os educadores a respeito da constituição psíquica da criança, avaliação inicial dos bebês que são cuidados por esses educadores e acompanhamento semanal dos educadores e bebês por meio dos IRDI (Ferrari, Silva \& Cardoso, 2013).

Partindo do pressuposto anteriormente discutido, de que o educador contribui para a constituição psíquica das crianças das quais cuida, a escola de educação infantil se torna um ambiente de suplência e continuidade dos cuidados promovidos no círculo familiar. Assim, a função da educação infantil deve ser discutida em diálogo com as funçôes desempenhadas pela mãe nos primeiros tempos de vida de seu bebê (Winnicott, 1977).

\section{MÉTODO}

A metodologia deste artigo constituiu-se em uma leitura pormenorizada dos indicadores da metodologia IRDI bem como de um estudo a respeito dos eixos teóricos que fundamentaram sua criação. Para isso, foram utilizadas referências como a tese de Pesaro (2009) que, em capítulo específico, esmiúça cada um dos eixos do instrumento, vinculando seu conteúdo aos respectivos indicadores. Em seguida, estudaram-se profundamente as teorizações de Winnicott sobre o início da vida psíquica do bebê, especialmente sobre os movimentos de integração do amadurecimento, a fim de propor como os IRDI poderiam ser lidos a partir de tal teoria. Nesse momento, contou-se com as contribuições de Omizzollo (2017), cujo trabalho já havia proposto uma interlocução entre os IRDI e a teoria de Winnicott.

Corroborando a possibilidade de diálogo entre as duas perspectivas teóricas em questão, Winnicott já evidenciava a importância da observação do bebê como instrumento de pesquisa. Para o autor, a criança pode fornecer importantes pistas de seu desenvolvimento emocional por meio de seu comportamento, visto que o bebê ainda é jovem demais para produzir material pela fala (Winnicott, 1993). Dessa forma, não pretendemos realizar uma correspondência artificial entre as diferentes perspectivas teóricas, mas sim propor uma ampliação do escopo do instrumento e da compreensão de seus indicadores.

Tendo em vista que este artigo busca enfatizar a posição do educador ${ }^{3}$ na constituição psíquica dos bebês, trabalharemos a contrapartida exigida desse

3 Embora, na rede de educação infantil de Porto Alegre, os termos "professora" e "educadora" possam ter conceituaçôes distintas, neste trabalho, eles foram usados como sinônimos. O mesmo vale para as expressões "creche" e "escola de educação infantil". 
profissional no amadurecimento das crianças das quais cuida: sustentação física, da subjetividade para certa objetividade, sobrevivência e acolhimento do gesto reparativo e atividade lúdica. Em suma, buscar-se-á encontrar nos IRDI pistas de onde se encontram os processos do desenvolvimento e por qual forma o educador pode contribuir para estes.

A esse respeito, a literatura afirma (Winnicott, 1957) que o educador amplia e suplementa o papel do cuidador primordial. Dessa maneira, compreendemos que este também auxilia a manter em marcha os mesmos processos acima citados: integração, personalização e contato com a realidade externa. Dessa forma, buscaremos, pela transposição do conceito de Winnicott de "mãe suficientemente boa” " para um "educador suficientemente bom”, compreender qual seria o papel desse profissional em sua prática com os bebês, em específico: de que maneira pode ajudar a criança a se manter existindo, garantindo sua continuidade de ser, de modo a suplementar o ambiente proporcionado pelo cuidador primordial?

\section{RESULTADOS E DISCUSSÃO: UM EDUCADOR SUFICIENTEMENTE BOM?}

O conceito de educador suficientemente bom é proposto e descrito por Rosa (1996) no que diz respeito às funções do educador em relação à sustentação do impulso criativo por meio do olhar e da corporeidade desse profissional. Mariotto (2009) também propõe a possibilidade de um investimento suficientemente bom por parte do educador, este contemplando tanto as atividades instrumentais dos cuidados cotidianos quanto o acolhimento psíquico do bebê. Nesse sentido, as tarefas de alimentar, vestir e limpar garantiriam não somente a sobrevivência física da criança, mas sua emergência como ser psíquico. Em termos winnicottianos, podemos considerar essa emergência como a capacidade do bebê de vir a ser alguém. Esse investimento suficientemente bom teria a característica de desvencilhamento dos modelos parentais, tornando desnecessário que a educadora aja "como se fosse" a mãe, mas tentando reconhecer a importância de seu acolhimento legítimo das crianças das quais cuida (Mariotto, 2009).

Ainda que as contribuições de Mariotto e Rosa pareçam apontar para uma direção comum, pretende-se realizar uma ampliação de tais ideias a partir da perspectiva de Winnicott e de uma releitura dos indicadores da metodologia IRDI. Assim, o conceito de educador suficientemente bom contemplaria: a sustentação física da experiência de ilusão, as vivências da transicionalidade, a capacidade de sobrevivência e o acolhimento do gesto reparativo da criança

$4 \mathrm{~A}$ mãe suficientemente boa é aquela que se adapta sensivelmente às necessidades de seu bebê, mantendo o mundo do bebê tão simples quanto possível, protegendo a criança das coincidências que podem exceder sua capacidade de compreensão (Winnicott, 1993). 
por parte do educador. Por fim, buscar-se-á traçar a importância do brincar na educação infantil, como um dos resultados últimos proporcionados por esse momento em específico do amadurecimento.

\subsection{Sustentação física}

O que o bebê necessita em seus primeiros meses de vida é um subsídio para começar a existir, dessa forma, as experiências ditas de "cuidado" podem ser muito mais significativas do que as pedagógicas, distantes da subjetividade em desenvolvimento da criança (Mariotto, 2009). Essas experiências, quando a criança começa a existir, ou habita ainda seu mundo subjetivo, dão-se pelo domínio físico. Dessa forma, vão exigir o "algo a mais", de modo que uma disponibilidade indisponível por parte do educador não é suficiente para incidir sobre a constituição psíquica da criança. $\mathrm{O}$ investimento que deve ser feito em relação aos bebês precisa partir da capacidade genuína do profissional de preocupar-se, bem como tolerar que seu corpo possa ser utilizado, possibilitando o início da existência para o bebê. Assim, entendemos que o educador pode ter um lugar nos processos de identificação primária e na posterior separação que vai ocorrendo do bebê e das figuras de cuidado, em direção a uma maior independência (Winnicott, 1983).

A ruptura na experiência familiar causada pelo ingresso na escola de educação infantil acarretaria o "problema psicológico" da adaptação, sendo, nesse exato ponto, que a professora pode se inserir, objetivando auxiliar essa transição, de maneira que essa experiência não se caracterize como uma interrupção do vir a ser da criança (Winnicott, 1957). Nesse momento, se o amadurecimento transcorreu bem, a criança já é capaz de lidar com as falhas ambientais, desde que não sejam demasiadas, então a realidade precisa agir de forma a não ultrapassar essas capacidades do bebê (Winnicott, 1990).

Compreendemos que, nesse período inicial, a educadora deve proporcionar uma experiência de identificação primária com a criança, baseada em sua própria identificação com alguma figura materna. Em resumo: a identificação da educadora com uma figura materna de cuidado deve possibilitar que esta, por sua vez, identifique-se com o bebê, a ponto de poder comparecer por meio de seu elemento feminino puro, ${ }^{5}$ assim contribuindo para a constituição psíquica da criança.

\footnotetext{
5 A teoria winnicottiana da sexualidade propõe uma compreensão não necessariamente libidinal e genital dos conceitos de elementos femininos e elementos masculinos em sua forma pura. Estes, antes do período da conflitiva edípica, correspondem apenas a formas de acesso aos objetos concedidas pelas figuras de cuidado primordial (Loparic, 2005). As experiências vinculadas ao elemento feminino puro possibilitariam a base da constituição psíquica, uma identificação primária e dependência absoluta em relação ao cuidador. A identificação por meio do elemento feminino puro exige pouca estrutura mental e fornece uma base para as possibilidades de ser desde o nascimento (Winnicott, 1975).
} 
Ao colocar-se nessa posição, a educadora torna-se mais empática em relação às necessidades do bebê, sendo capaz de sustentá-lo (hold) em termos físicos e psíquicos. O holding seria a forma pela qual o cuidador primordial acolhe e protege o bebê, estando também vinculado a uma capacidade empática em conseguir identificar-se com as necessidades da criança. $\mathrm{O}$ segurar não seria apenas físico, mas também a provisão ambiental, o aspecto real do relacionamento cuidadorcriança que precede a capacidade de "viver com", existindo como ser separado (Winnicott, 1983). Essa tendência estaria relacionada a uma maior integração, permitindo que a criança se sinta como um indivíduo e, consequentemente, maior delimitação entre os aspectos internos e externos.

Nesse ensejo, em um primeiro momento, é muito importante que o ritmo natural da criança domine a cena. Dessa forma, as rotinas de alimentação, sono, momentos de interação deveriam ser pensadas, nesses primeiros momentos, a corresponderem aos impulsos do bebê, tornando a escola adaptada às suas necessidades e não o contrário. Torna-se importante que as educadoras possam compreender as manifestações dos bebês, diferenciando suas necessidades. Esse aspecto é contemplado pelo IRDI por meio do indicador 1: "Quando a criança chora ou grita, a professora sabe o que ela quer".

Concluímos que, no início, é importante que o ritmo natural do bebê possa ser compreendido pela mãe e que ela responda por meio dos cuidados, como ocorre nas mamadas, por exemplo. $\mathrm{O}$ sucesso da experiência de alimentação está menos relacionado com a satisfação da necessidade de alimentar-se e mais com o estabelecimento de um padrão de comunicação e intimidade entre o bebê e a figura primordial de cuidado (Winnicott, 1990). Nesse sentido, pensamos que as experiências orais possam se realizar de forma a contribuírem para o fortalecimento do ego quando são realizadas em um contexto que proporciona uma satisfatória sustentação dessa vivência. Ir ao encontro da ilusão da criança, nesse momento, significa oportunizar uma experiência compartilhada, por exemplo: poder alimentar o bebê quando este sente fome; deixar que possa, se isso já for possível, comer sozinho, bem como ter paciência neste processo, tolerando que essa pode ser uma experiência complicada por diferentes fatores.

A alimentação é uma continuidade do que foi proporcionado pela mãe, então a educadora deve mostrar amor mediante esses cuidados e estar preparada para ser recusada (odiada e rejeitada) ou aceita (merecedora de confiança). A aceitação da alimentação como protótipo das experiências da oralidade demonstra a possibilidade de abertura do bebê em relação ao mundo externo. Assim, caso se fira o impulso criativo nesse momento, essa intrusão pode fazer com que o bebê se volte para si mesmo ou desenvolva uma existência falsa (Winnicott, 1983). 
Por outro lado, quanto maior a integração egoica, temporal e espacial da criança, menor a necessidade de adaptação por parte do cuidador. Seguindo a ideia da tendência inata para a integração, espera-se que a adaptação da criança ao ambiente da creche torne-se cada vez mais sólida. Assim o bebê vai se vinculando ao funcionamento da instituição de acordo com o momento de sua maturidade emocional. Aqui se torna importante mencionar o indicador de número 6 do IRDI, esperado na faixa etária dos 4 aos 8 meses: "A criança começa a adaptar-se à rotina da creche". Se presente, este parece estar traduzindo uma boa aceitação do ambiente de cuidados alternativos.

A forma pela qual o educador sustenta o bebê ainda propicia maior integração temporal, primeiro sentindo a presença física da figura de cuidado e, em seguida, pelas memórias que vão se acumulando em relação a essas experiências (Winnicott, 1975). A continuidade e previsibilidade da sustentação capacitaria a criança a criar expectativas e previsões do que virá a seguir, por exemplo, em consequência de uma vocalização dirigida à profissional da creche. Os indicadores 4 e 8 parecem mimetizar as primeiras experiências de integração temporal no amadurecimento do bebê: "4) A professora propõe algo à criança e aguarda a sua reação"; "8) A criança solicita a professora e faz um intervalo para aguardar sua resposta”.

É esperado que, progressivamente, a criança possa ir realizando "acordos" com o cuidador, sem que precise se submeter aos ritmos da instituição de educação infantil que, nesse momento, representa o mundo objetivo. Observa-se aqui a capacidade de o bebê conseguir suportar um tempo até que seja atendido, aspecto que aponta para a retenção da imagem do cuidador em seu psiquismo. Assim, a professora não precisa mais responder imediatamente às suas demandas, pois sua capacidade de reter memórias começa a ser possível.

No que diz respeito à manipulação do corpo do bebê, o educador deve disponibilizar seu corpo de forma que as experiências de reciprocidade física possam inaugurar a existência da criança. Da mesma forma que a comunicação mãe e criança dá-se, em um primeiro momento, silenciosamente, o educador precisa dar continuidade a essa linguagem corporal, respeitando suas manifestaçôes por meio do corpo, tanto seu quanto do bebê.

Aqui a maneira como o cuidador manipula o corpo da criança poderá facilitar ou não a consolidação dos processos de personalização, o qual se dá pela elaboração bastante primitiva do funcionamento corporal da criança. A integração espacial vai sendo possível nesse momento também, uma vez que o corpo se torna a primeira morada do indivíduo (Winnicott, 1983). 
Entretanto, nas instituições de educação infantil, muitas vezes, o cuidado acaba sendo organizado em razão da divisão de tarefas entre as educadoras. Frequentemente é compreendido que seria função da professora a tarefa de educar, enquanto a auxiliar seria quem se responsabilizaria pelo corpo do bebê. Assim, seguindo essa crença bastante difundida nas creches, o handling, em específico seria uma tarefa das auxiliares e estagiárias. O domínio do corpo ficaria relegado a um segundo plano, como um cuidado que, a princípio, pode ser realizado por educadoras que têm menor formação (Recktenvald, 2018). Contudo, Winnicott (1990) propõe que se a técnica de cuidado infantil é boa, não importa quem a está empregando. Nesse sentido, professora e auxiliar devem tanto cuidar quanto educar, pois, ao cuidar do corpo, na primeira infância, educa-se o sujeito (Mariotto, 2009).

Dada a precocidade dos processos de amadurecimento, nesses primeiros momentos, a elaboração imaginativa das funções corpóreas ${ }^{6}$ tem um caráter quase fisiológico, muito aproximado ao próprio funcionamento do corpo (Loparic, 2005). A existência vai sendo possível pelos sentidos gestuais e comportamentais lidos pela professora nas manifestações do bebê, em seu surgimento espontâneo, não ainda vinculados a representações.

Ainda que a comunicação nesses primeiros momentos seja mais relevante na reciprocidade da experiência física, espera-se que a professora possa ir aliando os cuidados a uma fala dirigida especialmente à criança que está sendo manejada. Nesse sentido, Winnicott demonstra que a importância de falar com os bebês residiria na forma com a qual o cuidador dirige-se à criança, mais do que o próprio conteúdo do que é dito (Winnicott, 1988). De modo semelhante, Guerra (2013) destaca a importância do ritmo na relação que se estabelece com o bebê, o qual se expressa também a partir da fala.

Assim, ao direcionar seu discurso de forma a alcançar e "fisgar" o bebê na interação, são esperadas as presenças dos seguintes indicadores: "2) A professora fala com a criança num estilo particularmente dirigido a ela (manhês)"; "5) Há trocas de olhares entre a criança e a professora"; "9) A educadora fala com a criança dirigindo-lhe pequenas frases".

A esse respeito, Rosa (1996) evidencia que, apesar de a palavra ser um dos instrumentos privilegiados da expressão, essa nunca é suficiente por si para abarcar a gama de comunicaçôes presentes no discurso. A fala enunciaria objetivamente o que é dito, mas as atitudes corporais transbordam e revelam um "como", que

6 A elaboração imaginativa das funçôes corpóreas diz respeito à capacidade de o bebê elaborar o funcionamento de suas partes do corpo, tornando-as elementos de sua experiência. Dessa forma, as manifestaçôes somáticas vão progressivamente adquirindo sentido, por meio de uma rudimentar catalogação e organização das experiências instintuais. O resultado desse processo é a experiência de ego, o ego corpóreo, que, ao longo do amadurecimento, torna-se uma fonte ativa de experiência pessoal, um si mesmo, ou, em outras palavras, um self(Winnicott, 1983). 
acaba não podendo ser escondido. Nesse sentido, a gestualidade, o tom de voz e a expressão no olhar formam um conjunto que tende a ser apreendido pelo bebê como o estilo de cada educador, sendo muito mais relevante para a constituição psíquica do que aquilo que é transmitido por palavras, pelo discurso. Assim, podemos pensar que o bebê vai experienciar e introjetar o modo como foi sustentado, não o conteúdo do que foi dito a seu respeito (Winnicott, 1988).

Sendo esses três indicadores supracitados pertencentes ao eixo suposição do sujeito no instrumento IRDI original, pensa-se que a voz (e o olhar) antecipem na criança alguém que ainda não está ali, mas precisa ser imaginado para começar a existir (Pesaro, 2010). Contudo, ao propor uma releitura winnicottiana desse processo, é necessário distinguir o que Lacan e Winnicott compreendem como a função do cuidador primordial nesse sentido.

A suposição do sujeito requer que o cuidador adicione elementos de seu próprio imaginário ao que vai sendo antecipado a respeito de certo bebê (Laznik, 2000). Entretanto, para Winnicott, a sensibilidade exacerbada em relação ao bebê, propiciada pela preocupação materna primária, permite a identificação do que a criança necessita no momento, sem a suposição de "algo a mais". Fica evidenciada a importância do bebê comparecendo espontaneamente e podendo ser acolhido em razão disso. Por esse motivo, Winnicott propõe que o olhar do cuidador primordial seja um espelho: o bebê precisa enxergar a si próprio e, caso enxergue o cuidador, sua tarefa de reunir-se torna-se imensamente dificultada. $\mathrm{O}$ olhar é contemplado pelo indicador de número 5, citado anteriormente, e pelo indicador 11 na faixa etária seguinte: "5) Há trocas de olhares entre a criança e a professora”; "11) A criança procura ativamente o olhar da professora".

Moratti e Lima (2014) demonstram a importância da reunião dos pedaços do corpo do bebê pelas educadoras da educação infantil, tanto pelos braços quanto pelo olhar dessas profissionais. Bebês que não são olhados (e não têm sua imagem refletida de volta) não terão seu corpo reunido e poderão experimentar sentimentos de desmembramento ou falta de sentido (Moratti, \& Lima, 2014).

Até aqui, a função da educadora parece contribuir mais para a capacidade de o bebê ser alguém do que em termos de enriquecimentos a um sujeito que já tem a capacidade de existir. Pode-se pensar que, nesse momento, a educadora deva subsidiar a possibilidade da criança de ser, sustentando sua existência nos termos discutidos. Os cuidados vão sendo inscritos como psíquicos, mediante o contato corpo a corpo, o olhar e a fala. Essa sustentação, em suplência ao que foi fornecido pela mãe, origina um espaço em que o bebê pode começar a ser ele mesmo. 
Pensamos que essas considerações auxiliem na desmistificação de alguns tabus presentes na educação, aqui, em específico, a crença de algumas profissionais de que não devem "dar muito colo" às crianças, em razão de não as mal acostumar. Parece importante ressaltar que, nesses momentos, ainda não existe um ego consolidado para que a atenção recebida possa ser compreendida como um mimo: até se estabelecer como alguém, a criança precisa ser reunida, tocada, afagada e investida. Esta se torna uma questão, em certo ponto, de "vida ou morte" psíquica, da possibilidade de existir ou continuar presa em um estado reativo de não integração e não ser.

Essa posição resistente ao afeto e cuidados pode ser compreendida em termos do que Safra (2009) denomina um eclipse do feminino, no momento histórico atual. Aqui o autor se refere ao feminino como o elemento feminino puro, aquele que, no começo da vida, permite o vir a ser do ser humano. Em contrapartida, estaríamos testemunhando, nos dias atuais, uma hipertrofia do masculino e do fazer, traduzido por uma postura mecanizada de repetir procedimentos padronizados, sem espaço para a subjetividade e espontaneidade. Seguindo essa tendência, as experiências vividas nos contextos de educação infantil da atualidade acabam não proporcionando momentos de quietude, continência e receptividade, trazendo prejuízos para o ethos humano (Safra, 2009).

\subsection{Da subjetividade para certa objetividade}

Se a educadora agiu até esse momento subsidiando o início da existência do bebê por meio da sustentação e possibilidade de experiência com o elemento feminino puro, sua tarefa em seguida se reveste de algumas complicaçôes. Quando a criança já está um pouco mais integrada, a tarefa principal da educadora se torna propiciar a experiência do elemento masculino, ou seja, o acesso à realidade (Safra, 2009). As experiências de sustentação do elemento feminino puro consolidaram o "ser" da criança; agora, sendo alguém, ela pode "fazer" coisas. Aqui o bebê se lança em direção ao mundo, na esperança do encontro com o objeto necessitado (Loparic, 2005).

A experiência de ilusão inaugura esse processo que culmina na capacidade da criação, por parte do bebê, do objeto sem o uso de uma representação preexistente (Safra, 2009). Por excelência, as primeiras mamadas seriam o protótipo da experiência de ilusão bem como as memórias sensoriais a essas vinculadas (Winnicott, 1975). Pensamos que seja impossível a professora reproduzir a experiência da mamada de forma totalmente fiel, porém deve seguir proporcionando um quantum de ilusão em seu modo de relacionar-se com os bebês. Como exemplificado a respeito da sustentação, uma amamentação 
satisfatória através da mamadeira ou a adaptação da rotina aos ritmos das crianças podem mimetizar certa experiência de ilusão por parte do ambiente da educação infantil.

Contudo, a ilusão precisa ir gradativamente sendo deixada de lado, por meio das vivências do elemento masculino que vão proporcionando uma objetificação da realidade. Aqui, Loparic (2005) aponta para a radicalidade e a importância desse momento do amadurecimento do bebê: mesmo que de forma progressiva, as vivências vão sofrendo uma total transformação, que passam de uma concepção subjetiva para a objetividade. Agora a tarefa da educadora é ir desiludindo o bebê, gradativamente. A percepção do mundo externo vai tornando o bebê apto a agir sobre esse mundo que está sendo descoberto, existindo espontaneamente e, por isso, agindo nessa realidade a qual passa a habitar.

Os indicadores que agora surgem (na faixa etária dos 4 aos 8 meses de vida do bebê) são pertencentes ao eixo do estabelecimento da demanda. Uma possível leitura winnicottiana desse conceito poderia ser a aquisição da capacidade para se relacionar. Nesse sentido, os indicadores parecem mostrar o direcionamento da criança em relação ao educador e às demais pessoas próximas: "7) A criança utiliza sinais diferentes para expressar suas diferentes necessidades"; "10) A criança reage (sorri, vocaliza) quando a professora ou outra pessoa está se dirigindo a ela”; "12) A professora dá suporte às iniciativas da criança sem poupar-lhe o esforço"; "13) A criança pede a ajuda de outra pessoa sem ficar passiva”.

$\mathrm{Na}$ escola, idealmente, existiriam oportunidades para o trânsito livre entre o sonho e o real em brincadeiras que empregam histórias, desenhos e música, fomentando as experiências de transicionalidade. $\mathrm{O}$ valor concedido à primeira possessão não eu vai espalhando-se para outros objetos. Dessa forma, na faixa etária dos 8 aos 12 meses, é esperado que os seguintes indicadores estejam presentes: "19.a) A criança possui objetos prediletos de casa”; "19.b) A criança possui objetos prediletos na creche".

Esses indicadores demonstram que a criança já pode desprender-se da figura de cuidado primordial, utilizando o polegar ou os objetos transicionais, de forma a satisfazê-la instintualmente e representar a mãe ou educadora, protegendo-se das ansiedades inimagináveis. $\mathrm{Na}$ ausência de objetos preferidos, é possível que a mãe ou a educadora ainda tenha uma importância muito grande como figura real, ainda não podendo ser representadas por outros meios.

Assim, quando as satisfações instintuais se encontram mais organizadas, a busca pelo objeto torna-se importante em razão da afetividade e não mais apenas pelas necessidades biológicas. Interagir agora traz prazer ao bebê, sendo que este se torna capaz de reagir positiva ou negativamente a algo, por encontrar-se mais 
integrado e podendo viver as experiências de modo criativo, em consonância com seu "ser". Ilustra essas conquistas a presença dos seguintes indicadores: "15) Durante os cuidados corporais, a criança busca ativamente jogos e brincadeiras amorosas com a professora”; "16) A criança demonstra gostar ou não de alguma coisa”; "18) A criança estranha pessoas desconhecidas para ela”; "20) A criança faz gracinhas".

$\mathrm{Na}$ última faixa etária abordada pelo IRDI (dos 12 aos 18 meses), a maior independência trazida pelos processos de objetificação pode ser traduzida através dos seguintes indicadores: "23) A professora alterna momentos coletivos com momentos de dedicação exclusiva à criança”; "24) A criança suporta bem as breves ausências da professora e reage às ausências prolongadas"; "26) A professora já não se sente mais obrigada a satisfazer tudo que a criança pede”.

\subsection{Sobrevivência}

Winnicott entende que a agressividade faz parte do impulso primitivo primário do bebê (Winnicott, 1993). Dessa forma, seria equivocado interpretar algumas das manifestaçôes orais ou de motilidade do bebê como decorrentes de sentimentos de ódio. A agressividade nesse início é, inclusive, uma das formas pelas quais a criança pode somaticamente começar a perceber o mundo externo.

$\mathrm{Na}$ relação do bebê com a mãe, foram estimulados na criança o amor e o ódio. Se a mãe pôde sobreviver a esses ataques, a criança passa a poder reunir o bom e o mau, originando o sentimento de culpa. A escola, portanto, deve seguir proporcionando a capacidade de reparação por meio da estabilidade de seu pessoal, de sua capacidade de não "revidar" a agressão da criança, e da provisão de brincadeiras que habilitem a criança a descobrir modos de enfrentar a culpa oriunda dos impulsos agressivos e destrutivos (Ribeiro, 2008).

A professora constitui o objeto de uma relação pessoal não materna, deve reconhecer que não é uma pessoa "vulgar" ou sem importância para o bebê. Nesse sentido, deve poder compreender que, nos primeiros momentos, será difícil para a criança conseguir aceitar que dê atenção aos coleguinhas (Winnicott, 1957). É só gradualmente, quando o bebê começa a construir um ambiente interno satisfatório, que aceitará ceder sua atenção para outras crianças sem ficar preocupada (Winnicott, 1983). Nesse momento, torna-se possível dividir sua atenção com os demais alunos, aspecto que é ilustrado, nos contextos de saúde, pelo indicador 23: "A professora alterna momentos coletivos com momentos de dedicação exclusiva à criança”. 
Nesse sentido, Winnicott também propõe a necessidade de, após momentos de maior integração do ego do bebê, as educadoras poderem proporcionar atividades em que a agressividade possa ser utilizada de forma a contribuir para o desenvolvimento (Rodman, 1990). Aqui é importante que possam conhecer um pouco da história de cada bebê, podendo pensar as formas de manejo mais apropriadas a cada caso: se a criança precisa de atividades de descarga direta de impulso, quando a raiva é acentuada, ou auxílio em relação à reparação e restituição, nos casos em que as fantasias de ódio e destruição são muito intensas (Winnicott, 1983).

Sendo vítimas de suas emoções muito fortes ainda em elaboração, a professora também pode auxiliar o bebê exercendo controle e orientação caso as crianças coloquem a si ou aos colegas em algum tipo (Ribeiro, 2008). Isso implica que essas profissionais possam estar preparadas para súbitas e dramáticas mudanças no comportamento, em razão de possíveis momentos de maior dependência, confusão entre o certo e errado, fato e fantasia, e propriedade pessoal e o que é pertencente aos outros (Winnicott, 1957). Nesse sentido, deve ser tolerante para lidar com essas situaçôes. Essas questôes são ilustradas pelos indicadores: "30) O professor coloca pequenas regras de comportamento para a criança”; “31) A criança diferencia objetos próprios dos da professora”.

Nesse momento, a criança tem uma ampla capacidade de modificar a realidade interna ou fantasia profunda por meio da realidade externa (Winnicott, 1983). Assim, a sobrevivência da professora como figura real permite que as fantasias internas possam ser postas à prova, reduzindo as ansiedades persecutórias relacionadas com a destruição imaginada do objeto.

\subsection{Acolhimento do gesto reparativo e atividade lúdica}

Quando a mãe ou o cuidador recebe o gesto reparador da criança, o bebê se torna livre para o amor instintivo. Winnicott (1983) propóe que a criança passaria a reconhecer e integrar os aspectos agressivos presentes no amor instintivo e as fantasias associadas, o que tornaria a vida instintual mais livre e os relacionamentos mais espontâneos, pois já não se encontrariam mais ameaçados pelas exigências provindas do id. Por esse motivo, se o gesto se depara com o vazio, da mesma forma que o corpo em queda para o elemento feminino (na ausência de sustentação), também são despertadas agonias, pois a ação perde-se por não encontrar um correspondente humano que a reconheça (Safra, 2009). A culpa se torna insuportável, invalidando a reparação, que passa a ser substituída por formas primitivas de ansiedade como o splitting e a desintegração (Winnicott, 1983). O mundo interno se torna cindido, habitado por experiências essencialmente más, 
evitando que o bebê possa atingir estados de tranquilidade (Winnicott, 1990).

Sendo a reparação a base do brincar e trabalhar construtivo, a ausência de um ambiente próximo e acolhedor do gesto reparativo também pode dificultar a capacidade para brincar e trabalhar construtivamente (Winnicott, 1990). Nos contextos de educação infantil, o papel do educador no que diz respeito ao brincar é bastante ativo, pois qualquer atividade significante para o desenvolvimento da criança está relacionada ao brincar: alimentação, digestão, entre outras (Mariotto, 2009).

Pode ser difícil compreender que um bebê já tenha a capacidade para brincar, pois sua criatividade e habilidade lúdica ainda se encontra em desenvolvimento. Nesse sentido, espera-se que o educador possa estar atento à linguagem das brincadeiras, na tentativa de compreender as diferentes manifestaçōes da criança que são expressas pelo brincar (Winnicott, 1957), mas sem "aniquilar" o impulso criativo, estando junto e auxiliando, proporcionando espaço para que a espontaneidade possa surgir.

Winnicott demonstra que a capacidade de a criança brincar evolui paralelamente aos processos do amadurecimento de cada indivíduo. Em um primeiro momento, a criança brinca com o corpo de seu cuidador, quando esse se apresenta de forma a corresponder à ilusão de criação onipotente do bebê (Winnicott, 1975). Nesse momento, ainda não existe uma separação não eu, sendo que a mãe ora é percebida pelo bebê subjetivamente, ora como ela realmente é.

Posteriormente, pelas progressivas experiências de transicionalidade, a criança passa a ser capaz de usufruir e brincar no espaço de ilusão (Winnicott, 1975). A confiança na mãe origina um playground intermediário, que comporta o interjogo do que é subjetivamente criado (e, por isso, controlado) e o que existe realmente, no mundo externo: elementos essenciais da brincadeira. Isso permite que a criança não necessite mais do corpo do cuidador, encontrando conforto e segurança por meio da sustentação concedida pelo olhar da profissional (Winnicott, 1983). Esses aspectos são ilustrados pelos indicadores $25 a$ e $b$, correspondentes à faixa etária dos 12 aos 18 meses do bebê: "25.a) A criança interessa-se pelo corpo da professora"; "25.b) A professora oferece brinquedos como alternativa para o interesse da criança por seu corpo".

A maior independência torna a atividade lúdica mais complexa. Caso participe da brincadeira, a educadora deve refletir o que ocorre no lúdico do indivíduo que brinca, sem adicionar elementos, em um primeiro momento. Na sequência, o bebê passa a ser capaz de brincar sozinho e, por fim, com outras crianças, já aceitando incrementos de seus pares ou cuidadores no brincar. 
A educadora deve poder traduzir em palavras as ações do bebê, espelhando o que ocorre no brincar, permitindo, assim, a simbolização e a encenação das diferentes representações e versōes da realidade e de si mesmo da criança. As atividades de aprender, investigar e desejar que surgem mais adiante no amadurecimento saudável são resultado desse brincar primitivo, e permitem que a criança também adquira o conhecimento por meio do lúdico e não somente pelo viés pedagógico (Ribeiro, 2008).

Dada a precariedade do interjogo próprio do período do amadurecimento da criança entre a percepção subjetiva e objetiva da realidade do brincar, as atividades lúdicas devem ainda possibilitar que a criança possa exercer certo controle mágico nesses momentos (Ribeiro, 2008). O bebê, nesses primeiros anos, vive no limite radical entre a fantasia e a realidade. Por esse motivo, os educadores são convidados a adentrar um mundo de histórias, contos e viagens imaginárias. $\mathrm{O}$ interesse na realidade vai se construindo aos poucos, e deve ser propiciado um ambiente que permita que a criança possa ir conhecendo todos os aspectos do mundo e ampliando suas experiências com a dose de ilusão necessária: "Tratando o adulto de não estragá-la antes do tempo da criança" (Ribeiro, 2008, p. 171).

\section{CONSIDERAÇÕES FINAIS}

Esta redescrição teórica demonstrou a possibilidade de interlocução entre os IRDI e a teoria winnicottiana do amadurecimento, resguardadas as especificidades dos conceitos que embasam o referido instrumento. Esse percurso teórico permitiu o embasamento do conceito de "educador suficientemente bom", ou seja, o que se espera da prática adequada de um educador de bebês do maternal e berçário. A presença de um ambiente suficientemente bom na educação infantil pressupóe a continuidade das funções exercidas pela mãe, quando o bebê é muito pequeno. Dessa forma, o educador segue proporcionando as experiências de integração egoica, temporal e espacial, personalização e apresentação da realidade externa aos bebês.

Este trabalho evidencia a necessidade de o educador implicar-se genuinamente em seus cuidados, pois estes não representam apenas a satisfação de necessidades biológicas, mas sim inscrições psíquicas que contribuem para o processo de amadurecimento das crianças. Aspectos como confiabilidade, previsibilidade e sustentação são decisivos nos primeiros tempos, demandando uma adaptação afinada do educador com as necessidades dos bebês. Progressivamente, os profissionais passam a ter a função de apresentar a realidade externa às crianças, por meio de vivências de transicionalidade. Mais tarde, o educador deve aceitar 
e acolher o gesto reparativo do bebê, subsidiando a atividade lúdica que passa a ser a base de toda a atividade cultural posterior.

Nesse sentido, a metodologia IRDI potencializa e sublinha a força do ato educativo como promotor da saúde mental nos primeiros anos de vida do bebê. Dessa forma, este trabalho reitera a importância dos educadores para a constituição psíquica dos bebês, aspecto que alude à necessidade de valorização e reconhecimento desses profissionais e do contexto da educação infantil, e de propostas de formação especializadas que contemplem tais aspectos. 


\section{REFERÊNCIAS}

Bernardino, L. M. F., \& Mariotto R. M. (2010). Psicanálise e educação infantil: diálogos a partir de uma pesquisa. Revista da Associação Psicanalítica de Curitiba, 10, 131-146.

Bernardino, L. M. F., Vaz, C., Quadros, M., \& Vaz, S. (2008). Análise da relação de educadoras com bebês em um centro de educação infantil a partir do protocolo IRDI. In R. Lerner, \& M. C. Kupfer (Orgs.), Psicanálise com crianças: clínica e pesquisa. (pp. 207-220). São Paulo: Escuta.

Ferrari, A. G., Silva, M. R., \& Cardoso, J. (2013). A metodologia IRDI na prevenção de risco psíquico em crianças que frequentam creche no seu primeiro ano e meio de vida. (Projeto de Pesquisa). Instituto de Psicologia, Universidade Federal do Rio Grande do Sul, Porto Alegre.

Guerra, V. (2013). Palavra, ritmo e jogo: fios que dançam no processo de simbolização. Revista de Psicanálise da SPPA, 20(3), 583-604.

Kupfer, M. C. M., Bernardino, L. M. F. \& Mariotto, R. M. M. (2014). Metodologia IRDI: uma intervenção com educadores de creche a partir da psicanálise. In De bebê a sujeito: a metodologia IRDI nas creches. (pp. 15-25). São Paulo: Escuta, FAPESP.

Kupfer, M. C. M., Jerusalinsky, A. N., Bernardino, L. F., Wanderley, D., Rocha, P. S. B., Molina, S. . . . Lerner, R. (2009). Valor preditivo de indicadores clínicos de risco para o desenvolvimento infantil: um estudo a partir da teoria psicanalítica. Revista Latino-Americana de Psicopatologia Fundamental, 13(1), $31-52$.

Kupfer, M. C. M., Rocha, P. S., Cavalcanti, A. E., Escobar, A. M. U., \& Fingerman, D. (2008). Apresentação e debate em torno da pesquisa multicêntrica do IRDI. In R. Lerner, \& M. C. Kupfer (Orgs.), Psicanálise com crianças: clínica e pesquisa. (pp. 49-62). São Paulo: Escuta.

Laznik, M. C. (2000). A voz como primeiro objeto da pulsão oral. Estilos da Clínica, 5(8), 80-93.

Loparic, Z. (2005, julho-dezembro). Elementos winnicottianos da teoria da sexualidade. Natureza Humana, 7(2), 311-358. 
Mariotto, R. M. M. (2009). A creche: da assistência à ciência. In Cuidar, educar e prevenir: as funçôes da creche na subjetividade de bebês. (pp. 23-44). São Paulo: Escuta, FAPESP.

Moratti, P., \& Lima, K. M. (2014). Integração psicossomática na constituição psíquica de bebês: os cuidados na creche. In Kupfer, M. C. M., Bernardino, L. M. F. \& Mariotto, R. M. M. (Orgs.), De bebê a sujeito: a metodologia IRDI nas creches. (pp. 223-238). São Paulo: Escuta, Fapesp.

Omizzollo, P. (2017). Experiências de (des)continuidade e o vir a ser no abrigo: desdobramentos a partir da teoria de D. Winnicott. (Dissertação de Mestrado). Programa de Pós-Graduação em Psicanálise: Clínica e Cultura, Universidade Federal do Rio Grande do Sul, Porto Alegre.

Pesaro, M. E. (2010). Alcances e limites teórico-metodológicos na pesquisa multicêntrica de indicadores clínicos de risco para o desenvolvimento infantil. (Tese de Doutorado). Programa de Pós-Graduação em Psicologia da Universidade de São Paulo, São Paulo.

Recktenvald, K. (2018). Os cuidados oferecidos aos bebês nas escolas de educação infantil e a capacidade de mentalização de educadores de berçário. (Dissertação de Mestrado), Universidade do Vale do Rio dos Sinos, São Leopoldo.

Ribeiro, M. J. (2008) O início das vivências escolares: contribuições da obra do psicanalista D. W. Winnicott. Aprender: Caderno de Filosofia e Psicologia da Educação, 2(11), 155-177.

Rodman, R. (1990). O gesto espontâneo: D. W. Winnicott. L. C. Borges (Trad.). São Paulo: Martins Fontes.

Rosa, S. S. (1996). A dissociação do selfe suas implicações na educação. Percurso - Revista de Psicanálise, 9(17), 75-83.

Safra, G. (2009). Os registros do masculino e feminino na constituição do self. Jornal de Psicanálise, 42(76), 77-89.

Winnicott, D. W. (1957). A criança e seu mundo. A. Cabral (Trad.). Rio de Janeiro: Zahar Editores.

Winnicott, D. W. (1975). O brincar e a realidade. J. O. A. Abreu, \& V. Nobre (Trads.). Rio de Janeiro: Imago. 
Winnicott, D. W. (1977). A criança e seu mundo. A. Cabral (Trad.). Rio de Janeiro: Jorge Zahar.

Winnicott, D. W. (1983). O ambiente e os processos de maturação. Porto Alegre: Artes Médicas.

Winnicott, D. W. (1988). Os bebês e suas mães. São Paulo: Martins Fontes.

Winnicott, D. W. (1990). Natureza humana. D. L. Bogomoletz (Trad.). Rio de Janeiro: Imago.

Winnicott, D. W. (1993). D. W. Winnicott: da pediatria à psicanálise. Rio de Janeiro: Francisco Alves. 